\title{
Remoção de $\operatorname{Cr}(V I)$ de soluções aquosas utilizando bentonita cálcica e pó de quiabo (abelmoschus esculentus) por processo de coagulação-floculação
}

\author{
V. L. OLIVEIRA ${ }^{1}$, E. JESUS ${ }^{1}$, e D. CONCEIÇÃO ${ }^{1}$ \\ ${ }^{1}$ Universidade Federal de Sergipe, Departamento de Engenharia Química \\ E-mail para contato: vivi_los@hotmail.com
}

\begin{abstract}
RESUMO - Este trabalho teve com objetivo avaliar a eficiência do uso de pó de quiabo e da bentonita cálcica como alternativa para remoção de $\mathrm{Cr}(\mathrm{VI})$ de efluentes industriais através da técnica de tratamento por processo de coagulação-floculação. Foram realizados testes em sistema de batelada contendo $\mathrm{Cr}(\mathrm{VI})$, sendo as concentrações determinadas por espectrofotometria UV-VIS via complexação dos íons $\mathrm{Cr}(\mathrm{VI})$ com difenilcarbazida. Foi estudada a influência do tempo de mistura lenta, $\mathrm{pH}$ da solução, concentração utilizada da bentonita e da massa de pó de quiabo. $\mathrm{O}$ pó de quiabo, a bentonita cálcica e o lodo pós-sedimentação foram caracterizados por Fluorescência de Raios-X (FRX), Espectroscopia de Absorção na Região do Infravermelho (FTIR). A remoção de $89,6 \%$ de $\mathrm{Cr}$ (VI) foi observada nas seguintes condições: tempo de mistura lenta de 30 minutos, $\mathrm{pH}$ da solução igual a 2 , concentração utilizada de pó de quiabo de $0,6 \mathrm{gL}^{-1}$ e concentração utilizada da bentonita de $0,6 \mathrm{gL}^{-1}$.

Palavras-chave: Cromo hexavalente; pó de quiabo; coagulação-floculação.
\end{abstract}

\section{INTRODUÇÃO}

A atividade industrial constitui a principal fonte antropogênica de contaminação por metais pesados, pois gera grandes volumes de efluentes líquidos contendo metais em concentrações acima das permitidas pela legislação ambiental vigente, representando uma importante fonte de contaminação dos corpos aquáticos, principalmente quando consideramos que tais íons podem ser disseminados via cadeia alimentar.

Os efluentes industriais contendo metais pesados, tais como chumbo, cromo, níquel, mercúrio e ferro, são atualmente uns dos mais sérios problemas na área ambiental. Estes metais são tóxicos até mesmo em baixas concentrações e não são compatíveis com a maioria dos tratamentos biológicos, descartando-se então a possibilidade de descarga desses efluentes na rede pública para tratamento em conjunto com o esgoto doméstico.

O tratamento clássico de efluentes contendo metais pesados envolve processos físicoquímicos de precipitação química, troca iônica, adsorção, separação com membranas, tratamento eletroquímico e extração por solventes (Zouboulis 2004, Humán 2005). A precipitação química é um método bastante utilizado por ser simples e econômico, mas que gera um grande volume 
de lodo e pode apresentar concentrações residuais de metais acima das normas de lançamento vigentes, sendo necessária a aplicação de um processo complementar para a adequação final do efluente (Dal Bosco 2006 e 2007). Sendo assim, estas técnicas tradicionais são de baixa eficiência operacional e com elevados custo operacional, sendo importante a busca por matérias que venham a diminuir o custo operacional destes processos.

Materiais alternativos têm sido utilizados em tratamento de água, principalmente na coagulação e floculação. Os polímeros não iônicos e os aniônicos são usados como auxiliares de floculação em conjunto com o coagulante primário. A maior vantagem do uso desses auxiliares é a formação de flocos mais resistentes às forças de cisalhamento, possibilitando floculação com gradientes mais elevados, com formação de flocos mais densos e com maior velocidade de sedimentação.

Assim, o desenvolvimento desse trabalho justifica-se pelo fato do crescimento contínuo de atividades industriais que contribuem para um aumento significativo de íons metálicos no meio ambiente, os quais são prejudiciais à vida dos seres.

Os efluentes contendo metais pesados necessitam de tratamento adequado para que possam obedecer aos padrões de emissão estabelecidos pelo Conselho Nacional do Meio Ambiente (CONAMA 2005, 2008). Atualmente, a remoção principalmente de Cr(VI) dos efluentes industriais tem se tornado assunto de grande interesse ambiental devido à alta toxicidade e das propriedades carcinogênicas, mesmo em baixas concentrações.

\section{MATERIAIS E MÉTODOS}

\subsection{Obtenção do pó de quiabo}

O pó de quiabo foi obtido a partir da secagem e trituração da vagem de quiabo. Foram pesados $1,088 \mathrm{~kg}$ de quiabo. A secagem procedeu em estufa da Sterilifer modelo SX 1.0, a $150{ }^{\circ} \mathrm{C}$ durante 4 horas. Após a secagem, as vagens do quiabo foram trituradas em processador comum de alimentos. Foi utilizado pó de quiabo com 100 mesh nos ensaios de remoção de $\mathrm{Cr}(\mathrm{VI})$.

\subsection{Determinação de $\operatorname{Cr}(V I)$ por Espectrofotometria UV-VIS via complexação com difenilcarbazida}

Foram preparadas, por diluições, a partir da solução padrão de cromo a 100 ppm em estoque, soluções nas concentrações padrões de 0,$2 ; 0,4 ; 0,6 ; 0,8$ e 1,0 ppm para construção da curva de calibração. O método utilizado para determinação do teor de $\mathrm{Cr}(\mathrm{VI})$ foi o da 1,5 difenilcarbazida (DFC) segundo Morita e Assumpção(2007).

\subsection{Testes em batelada de remoção do $\mathrm{Cr}$ (IV) por coagulação-floculação}

A solução padrão de cromo utilizada neste trabalho foi preparada a partir do dicromato de potássio $\left(\mathrm{K}_{2} \mathrm{Cr}_{2} \mathrm{O}_{7}\right)$. Foram pesados $0,2829 \mathrm{~g}$ de dicromato de potássio, previamente aquecido em estufa a $140{ }^{\circ} \mathrm{C}$ por uma $1 \mathrm{~h}$, uma solução padrão de $100 \mathrm{ppm}$ de 
$\mathrm{Cr}(\mathrm{VI})$. Os testes de remoção do $\mathrm{Cr}(\mathrm{VI})$ foram feitos utilizando o Jar test modelo JT 102.3 da Milan. As amostras foram submetidas a 1 minuto de mistura rápida a $150 \mathrm{rpm}$, adotando parâmetros da ETA-POXIM localizada em Aracaju. No início desta etapa, adicionou-se 1 mL do coagulante $\mathrm{Fe}_{2}\left(\mathrm{SO}_{4}\right)_{3}$ em todos os testes de remoção de $\mathrm{Cr}(\mathrm{VI})$. Em seguida, a velocidade de agitação foi reduzida para $30 \mathrm{rpm}$ iniciando o processo de mistura lenta, proporcionando o crescimento dos flocos.

Depois de 15 minutos de sedimentação livre foram coletadas amostras do sobrenadante para análise. O ponto de referência para a coleta de cada amostra foi de aproximadamente $2 \mathrm{~cm}$ de profundidade em relação à superfície livre. As concentrações de $\mathrm{Cr}(\mathrm{VI})$ das amostras foram determinadas por complexação com difenilcarbazida. O percentual de remoção de $\mathrm{Cr}(\mathrm{VI})$ foi calculado pela Equação 1.

$$
\% \text { Remoção de Cromo }(V I)=\left[\frac{\left(C_{i}-C_{f}\right)}{C_{i}}\right] 100
$$

onde $C_{i}$ e $C_{f}$ são concentrações inicial e final de $\mathrm{Cr}(\mathrm{VI})$ respectivamente.

\subsection{Efeito do tempo de mistura lenta na remoção de $\operatorname{Cr}(\mathrm{VI})$}

A remoção de $\mathrm{Cr}(\mathrm{VI})$ foi determinada tomando-se diversos tempos de mistura lenta $(15,20,25,30$ e 35 minutos). A concentração de $\mathrm{Cr}$ (VI) inicial utilizada foi de $2 \mathrm{ppm}$ utilizando $\mathrm{pH}$ inicial da solução aquosa igual 2. A massa de bentonita cálcica utilizada foi $0,3 \mathrm{~g}$ (100 mesh) e a massa de pó de quiabo foi $1,0 \mathrm{~g}$.

\subsection{Efeito do pH, da massa de pó de quiabo e da massa de bentonita na remoção de $\operatorname{Cr}(V I)$}

A influência do $\mathrm{pH}$ na remoção de $\mathrm{Cr}(\mathrm{VI})$ foi analisada no $\mathrm{pH}$ inicial da solução igual a 2, 4 e 6, concentração de $2 \mathrm{ppm}$ de $\mathrm{Cr}(\mathrm{VI}), 30 \mathrm{mim}$ de mistura lenta, 0,3 g de bentonita cálcica, $1,0 \mathrm{~g}$ de pó de quiabo e mistura rápida de $1 \mathrm{~mm}$. $\mathrm{O} \mathrm{pH}$ inicial das soluções foi ajustado utilizando solução $1,0 \mathrm{M}$ de $\mathrm{NaOH}$ e solução $1,0 \mathrm{M}$ de $\mathrm{HCl}$. Na análise da influência da massa de pó de quiabo foi utilizada 0,$2 ; 0,3 ; 0,6 ; 1,0$ e 1,4 g de pó de quiabo, concentração inicial de $2 \mathrm{ppm}$ de $\mathrm{Cr}(\mathrm{VI})$, pH inicial da solução igual a 2, 0,3 g de bentonita cálcica. Na influência da massa de bentonita cálcica foram utilizadas as massas de 0,$2 ; 0,3 ; 0,6 ; 1,0$ e 1,4 g, com concentração inicial de 2 ppm de $\mathrm{Cr}(\mathrm{VI})$ e pH inicial da solução igual a 2 e massa de pó quiabo previamente determinada pelo procedimento anterior.

\subsection{Fluorescência de raios-X}

A preparação da amostra foi feita com o ácido bórico, onde foi misturado no almofariz $0,5 \mathrm{~g}$ da amostra com 4,5g de ácido bórico P.A., transferido para um pastilhador, sendo a amostra prensada. Nesse procedimento, a amostra é colocada em uma cubeta de 34 $\mathrm{mm}$ de diâmetro, o modo de análise foi o vácuo separado e o método escolhido foi o best detection. O equipamento utilizado foi o espectrômetro modelo S8 Tiger da Bruker. 


\section{RESULTADOS E DISCUSSÃO}

A maior taxa de remoção de $\mathrm{Cr}(\mathrm{IV})$ ocorreu em meio ácido. Em média a remoção foi de $78,23 \%$ no $\mathrm{pH} 2$. Este comportamento pode ser explicado em decorrência do aumento do número de íons hidrônios no meio, o que favorece positivamente a modificação da superfície tanto argila como do pó de quiabo, em decorrência da protonação.

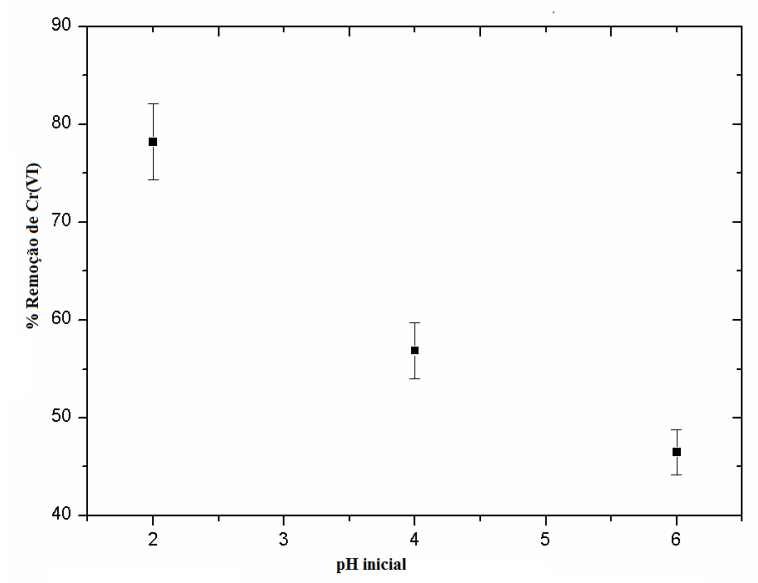

Figura 1 - Efeito do pH na remoção de Cr(IV). (Condições: concentração inicial de $\mathrm{Cr}(\mathrm{VI})$, 2 ppm; quantidade de pó de quiabo $1 \mathrm{~g}$ (100 mesh), quantidade de argila 0,3 g (100 mesh); temperatura $25 \pm 1{ }^{\circ} \mathrm{C}$; tempo de mistura lenta $30 \mathrm{~min}$ ).

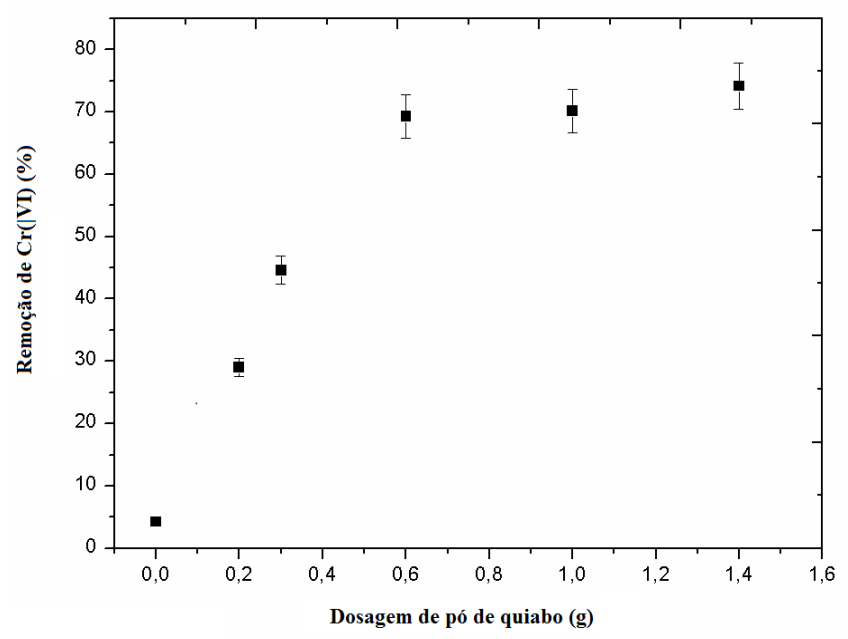

Figura 2 - Efeito da dosagem do pó de quiabo na remoção de $\mathrm{Cr}(\mathrm{IV})$. (Condições: concentração inicial de $\mathrm{Cr}(\mathrm{VI}), 2$ ppm; pH 2; quantidade de argila 0,3 g (100 mesh); temperatura $25 \pm 1{ }^{\circ} \mathrm{C}$; tempo de mistura lenta $30 \mathrm{~min}$ ).

Diversos trabalhos mostram a remoção de metais pesados por adsorção usando $\mathrm{pH}$ ácido, a exemplo dos trabalhos com levedura Yarrowia lipolytica (Rao et al. 2013), folhas de Araucária secas (Shukla e Vankar 2012), cascas de nozes (Altun and Pehlivan 2012), casca e polpa de Laranja Osage (Pehlivan et al. 2012a), cascas de jabuticaba (Oliveira and Silva 2011) e pó da casca de coco verde (Huamán Pimo 2005). O pH ácido favorece 
ligações de espécies de íons de $\mathrm{Cr}(\mathrm{VI})$ com os grupos carregados positivamente (Pehlivan et al. 2012a, Pehlivan et al. 2012b).

A influência do $\mathrm{pH}$ na ação de remoção do $\mathrm{Cr}$ (IV) pode ser vista através dos resultados apresentados na Figura 1. Quando os grupos orgânicos oxigenados e nitrogenados encontram-se protonados, o pó de quiabo pode interagir com as espécies aniônicas de $\mathrm{Cr}(\mathrm{VI})$, tipicamente por meio de interações eletrostáticas, ligações de hidrogênio e interações hidrofóbicas. Sendo o pó de quiabo rico em substâncias, a exemplo de polissacarídeos e proteínas (Mota et al. 2005), que apresentam hidroxilas em suas estruturas, as quais atraem íons $\mathrm{H}^{+}$que por sua vez interagem com os oxiânios $\mathrm{HCrO}_{4}{ }^{-} \mathrm{e}$ $\mathrm{Cr}_{2} \mathrm{O}_{7}^{2-}$ presentes na solução em $\mathrm{pH} 2$.

A influência da dosagem do pó de quiabo na remoção do $\mathrm{Cr}(\mathrm{IV})$ é mostrada na Figura 2. É possível observar que nas concentrações de 0,6 e $1,0 \mathrm{gL}^{-1}$ as porcentagens de remoção do $\mathrm{Cr}(\mathrm{VI})$ apresentaram valores bem próximos, 69,28\% e 70,10\% respectivamente. Para concentrações acima de $0,6 \mathrm{gL}^{-1}$ de pó de quiabo começou a ocorrer o processo de reestabilização dos coloides o que diminui a influência da massa do pó de quiabo na remoção. Nota-se também pela Figura 2 a baixa remoção de $\mathrm{Cr}(\mathrm{VI})$, em torno de $5 \%$, quando não utiliza o pó de quiabo.

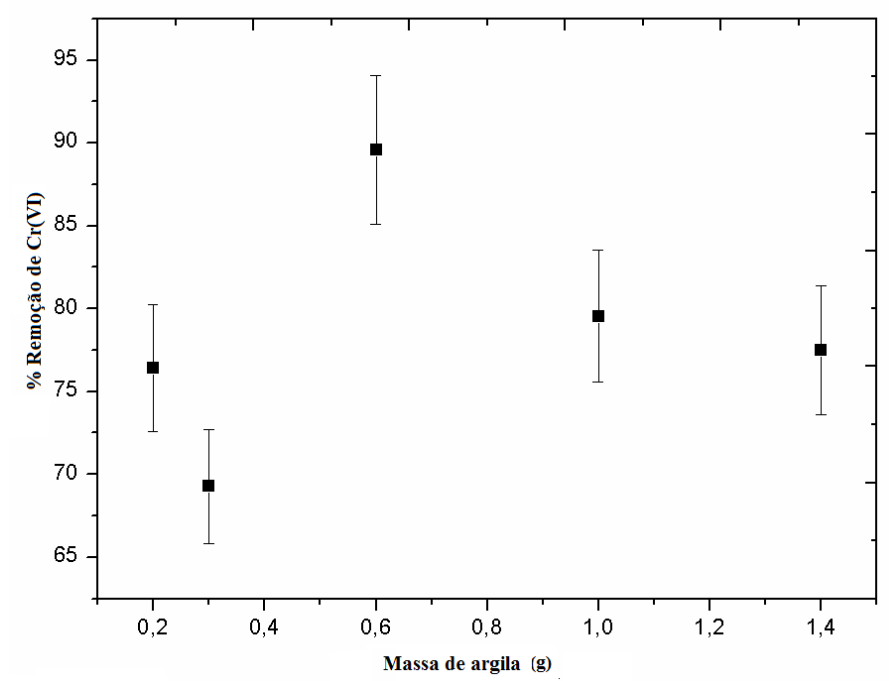

Figura 3 - Influência da massa de argila na remoção de $\mathrm{Cr}(\mathrm{VI})$. (Condições: concentração inicial de $\mathrm{Cr}(\mathrm{VI}), 2$ ppm; pH 2; quantidade do pó de quiabo 0,6 g (100 mesh); temperatura $25 \pm 1^{\circ} \mathrm{C}$; tempo de mistura lenta $30 \mathrm{~min}$ ).

A influência da massa de argila é mostrada na Figura 3. A argila juntamente com o pó de quiabo removeu, em média, de $89,58 \%$ quando utilizados numa dosagem de $0,6 \mathrm{gL}^{-1}$. Como pode ser observado na Figura 3, a quantidade de $\mathrm{Cr}(\mathrm{IV})$ removida aumenta com o aumento da quantidade de massa da argila até $0,6 \mathrm{~g}$. Houve diminuição na remoção do metal quando se aumentou de $0,6 \mathrm{gL}^{-1}$ a dosagem de argila. Este comportamento pode ser atribuído ao fato de que uma maior quantidade de massa aumenta a quantidade de área superficial do material e, com isso, há mais sítios disponíveis para a adsorção (Clark 2010, Hamzeh et al. 2012).

Rocha et al. (2005) utilizaram Saccharomyces cerevisiae na remoção de cromo de efluentes usando adsorção, conseguindo $80 \%$ de remoção em 8 horas de tempo de contato. 
Veit et al. (2009) investigaram a remoção dos íons cromo e níquel presentes no efluente do processo de galvanoplastia pela biomassa de alga marinha pré-tratada Sargassum filipendula. Pehlivan et al. (2012a) usaram casca de laranja na remoção de $\mathrm{Cr}(\mathrm{VI}) \mathrm{com}$ $78 \%$ e de polpa da laranja com $88 \%$ de remoção. Huamán (2005) utilizou casca de coco verde removendo $85 \%$ de remoção de $\mathrm{Cr}(\mathrm{VI})$ usando dosagem de $5 \mathrm{gL}^{-1}$. O processo de coagulação-floculação adotado neste trabalho utilizando pó de quiabo e bentonita cálcica removeu aproximadamente $90 \%$ em 30 minutos.

A presença de cromo no lodo foi evidenciada por fluorescência de raios-X (FRX). A análise da mostrou os principais componentes: $\mathrm{SiO}_{2}(70,34 \%), \mathrm{Al}_{2} \mathrm{O}_{3}(16,07 \%)$ e $\mathrm{Fe}_{2} \mathrm{O}_{3}$ $(6,54 \%)$. O pó de quiabo é um composto orgânico rico e proteínas e polissacarídeos (Mota et al. 2005), formado predominantemente por carbono e hidrogênio. Os principais elementos expressos em óxidos que o pó de quiabo apresentou foram $\mathrm{CaO}(28,20 \%), \mathrm{SO}_{3}$ $(5,16 \%), \mathrm{K}_{2} \mathrm{O}(44,22 \%)$ e $\mathrm{P}_{2} \mathrm{O}_{5}(8,99 \%)$.

Assim como na argila, nota-se que no lodo as principais espécies metálicas foram $\mathrm{Si}$, $\mathrm{Al}$ e Fe. O lodo obtido apresentou teor de $\mathrm{Fe}_{2} \mathrm{O}_{3}$ de 5,10\%. Alguns elementos presentes somente no pó de quiabo, a exemplo do $\mathrm{P}$, foram detectados no lodo gerado após o processo coagulação-floculação, mostrando que o pó interfere no processo. Em relação ao $\mathrm{Cr}_{2} \mathrm{O}_{3}$ o lodo obtido com uso de pó de quiabo apresentou percentual de $0,15 \%$. Notou-se também que a espécie Ca presente no pó de quiabo se refletiu no lodo com percentual bem baixo, indicando possível transporte deste para o meio aquoso, denotando espécie de cátions trocáveis.

\section{CONCLUSÃO}

Os resultados obtidos neste trabalho evidenciaram que o pó de quiabo (Abelmoschus esculentus) juntamente com a bentonita cálcica tem um forte potencial na remoção de $\mathrm{Cr}(\mathrm{VI})$ de soluções aquosas por processo de coagulação-floculação. O pó de quiabo mostrou-se ser eficaz no processo de coagulação-floculação para a remoção de $\mathrm{Cr}(\mathrm{VI})$. $\mathrm{O}$ pH é uma variável importante, que deve ser controlada para se obter uma alta eficiência no processo de remoção. $\mathrm{O}$ estudo aqui apresentado mostra que o valor de $\mathrm{pH}$ ótimo para a remoção do $\operatorname{Cr}(\mathrm{VI})$ foi de 2,0. A bentonita cálcica quando foi usada sem o pó de quiabo não apresentou resultados satisfatórios na remoção do metal, isso pode ser explicado pelo fato de que as partículas coloidais de argilas naturais possuem propriedades elétricas que criam uma força de repulsão que impede a aglomeração e a sedimentação. O uso do pó de quiabo proporcionou um aumento da atração eletrostática favorecendo a remoção do íon metálico.

\section{REFERÊNCIAS}

ALTUN, T.; PEHLIVAN, E. Removal of Cr(VI) from aqueous solutions by modified walnuts shells. Food Chemistry, v. 132(2), p. 693-700, 2012.

BRASIL, CONAMA. Resolução $n^{\circ} 357$, de 2005, que dispõe sobre a classificação dos corpos de água e diretrizes ambientais para o seu enquadramento, bem como estabelece as condições e padrões de lançamento de efluentes. Diário Oficial da República Federativa do Brasil, Brasília, DF, 03 de abril de 2008.

BRASIL, CONAMA. Resolução no 397, de 03 de abril de 2008. Altera o inciso II do $\S 4^{\circ}$ e a Tabela X do $\S 5^{\circ}$, ambos do art. 34 da Resolução do Conselho Nacional do Meio Ambiente, Brasília, DF, 03 de abril de 2008. 
CLARK, H. L. M. Remoção de Fenilalanina por adsorventes produzido a partir da torta prensada de grãos defeituosos de café. (2010). Dissertação (Mestrado em Ciência dos Alimentos), Universidade Federal de Minas Gerais, Belo Horizonte-MG, Brasil.

DAL BOSCO, S. M. Remoção de Cromo de Solução Aquosa Utilizando Rocha Sedimentar Contendo Zeólita. 2007. 46 f. Dissertação (Mestrado em Geociências) Programa de Pós-Graduação em Geociências, Universidade Estadual de Campinas, Campinas - SP, Brasil, 2007.

DAL BOSCO, S. M.; VIGNADO, C.; CARVALHO, W. A. Adsorção de Mn(II) e Cd(II) por Argilas In Natura e Modificadas com Pirrolidinaditiocarbamato de Amônio. Geochimica Brasiliensis, v. 20 (3), p. 219-232, 2006.

HAMZEH Y.; ASHORI A.; AZADEH E.; ABDULKHANI, A. Removal of Acid Orange 7 and Remazol Black 5 reactive dyes from aqueous solutions using a novel biosorbent. Materials Science and Engineering, 32(6), p. 1394-1400, 2012.

HUAMÁN PINO, G. A. Biossorção de Metais Pesados Utilizando Pó da Casca de Coco Verde (Cocos nucífera). 2005. 113f. Dissertação (Mestrado em Engenharia Metalúrgica) - Programa de Pós-Graduação em Engenharia Metalúrgica, Pontifícia Universidade Católica do Rio de Janeiro, Rio de Janeiro - RJ, Brasil, 2005.

MORITA, T.; ASSUMPÇÃO, R.M. Manual de Soluções, Reagentes e Solventes. 2 ed., São Paulo: Edgard Blucher, 2007.

MOTA W. F; FINGER, F. L.; SILVA, D. J. H.; CORREAA, P. C.; FIRME, L. P., NEVES, L. L. M. Caracterização físico-química de frutos de quatro cultivares de quiabo. Horticultura brasileira, v. 23, p. 722-725, 2005.

OLIVEIRA R.; SILVA, R. C. O. Biossorção de cromo (VI) utilizando cascas de jabuticaba. Trabalho de conclusão de curso (Bacharelado em Química). Universidade Tecnológica Federal do Paraná (UTFPR). Pato Branco, 2011.

PEHLIVAN E.; PEHLIVAN E.; TUTAR K. H. Hexavalent chromium removal by Osage Orange. Food Chemistry, v. 133, p. 1478-1484, 2012a.

PEHLIVAN, E.; ALTUN, T.; PARLAYICI, S. Modified barley straw as a potential biosorbent for removal of copper ions from aqueous solution. Food Chemistry, v. 135, p. 2229-2234, 2012b.

RAO, A.; BANKAR, A.; KUMAR, A. R.; GOSAVI, S.; ZINJARDE, S. Removal of hexavalent chromium ions by Yarrowia lipolytica cells modified with phyto-inspired $\mathrm{Fe}$ /Fe3O4 nanoparticles. Journal of Contaminant Hydrology, v.146, p. 63-73, 2013. ROCHA, E. R. L.; MARCATO, V. J.; COSSICH, E. S. Biossorção de cromo por biomassa de saccharomyces cerevisiae. In: VI CONGRESSO BRASILEIRO DE ENGENHARIA QUÍMICA EM INICIAÇÃO CIENTÍFICA, 2005, São Paulo.

SHUKLA, D.; VANKAR, P. (2012). Efficient biossorption of chromium(VI) ion by dry Araucaria leaves. Environmental Science and Pollution Research, 19(6): 23212328.

VEIT, M. T. et al. Biossorção de níquel e cromo de um efluente de galvanoplastia utilizando alga marinha pré-tratada em coluna. Acta Scientiarum. Technology, v. 31 (2), p. 175-183, 2009.

ZOUBOULIS, A.I.; LOUKIDOU, M.X.; MATIS, K. A. Biosorption of toxic metals from aqueous solutions by bacteria strains isolated from metal-polluted soils. Process Biochemistry, v. 39, p. 909-916, 2004. 